\title{
Magnetic Biopolymeric Hydrogel Composite Material with Self-healing Attribute
}

\author{
Nurzeba C. Sanoh ${ }^{1}$, Gerlone M. Salazar ${ }^{1}$, David P Penaloza Jr. 1, * (D) \\ 1 Chemistry Department, College of Science, De La Salle University, 2401 Taft Avenue, Manila 0922 Philippines \\ * Correspondence: david.penaloza.jr@dlsu.edu.ph
}

Received: 22.02.2021; Revised: 18.03.2021; Accepted: 21.03.2021; Published: 2.04.2021

\begin{abstract}
This work presents a polysaccharide-based magnetic self-healing hydrogel fabricated through the incorporation of surface modified magnetic nanoparticles, a silica-surface modified magnetic- $\mathrm{Fe}_{3} \mathrm{O}_{4} @ \mathrm{SiO}_{2}$, (MNP), to a polymer composite synthesized from the oxidation of xanthan gum (XG) and it's crosslinking with chitosan (CS) to generate Schiff base linkages rendering selfhealing character. Fourier transform infrared (FT-IR) spectroscopy analyses revealed the successful formation of Schiff base bonding in the CS-OXG and CS-OXG-MNP hydrogels. In incorporating surface-modified magnetic nanoparticles, the resulting CS-OXG-MNP hydrogel with a weight ratio of 1:1:0.2, respectively, exhibited a better self-healing hydrogel in terms of faster self-healing characteristics and stronger mechanical property.
\end{abstract}

Keywords: hydrogel; biocomposite; self-healing; magnetic nanoparticle.

(C) 2021 by the authors. This article is an open-access article distributed under the terms and conditions of the Creative Commons Attribution (CC BY) license (https://creativecommons.org/licenses/by/4.0/).

\section{Introduction}

Hydrogels are interesting materials capable of trapping a large amount of liquid (usually water) through their crosslinked structures. This makes them comparable to natural extracellular matrices, making them efficient biocompatible materials. Moreover, hydrogels also have a porous structure and are suitable to take in high amounts of water-soluble compounds [1-9], which is important for a broad range of biomedical and industrial applications such as drug delivery, tissue engineering, and adsorbents [10-14]. Crosslinks can be in the form of strong chemical linkages (e.g., covalent, ionic bonds), physical entanglements, or weak interactions (like hydrogen bonds) [2, 6, 15]. Adding self-healing character renders these materials a remarkable, unique property usually associated with natural organisms - the ability to heal when certain damages and injuries occur. Such smart materials can lead to a gamut of commercial applications - drug delivery, implant coatings, tissue engineering, artificial muscles, etc.

On the other hand, magnetic nanoparticles (MNPs) are exceptionally minuscule particles that measure from 1-100 nm, paramagnetic, and usually made of magnetic elements such as iron, nickel, cobalt, and their oxides. Over the years, MNPs have been a wide-ranging research topic due to their many possible applications due to their high surface area, magnetism, and biocompatibility [16-22]. Magnetite $\left(\mathrm{Fe}_{3} \mathrm{O}_{4}\right)$ nanoparticles are ideal candidate filler materials for hydrogels as they are widely used for biomedical applications [19, 23-28]. They are also employed in wastewater purification, specifically for adsorbing arsenite, cadmium, 
nickel and alkalinity and hardness adjustments, and desalination efforts. By a simple magnetic process, $\mathrm{Fe}_{3} \mathrm{O}_{4}$ can be separated from the medium after adsorption [28-32].

This work introduces self-healing capability to a hydrogel composite system made from ubiquitously abundant biopolymers, chitosan, and xanthan gum filled with modified magnetic nanoparticles. Crosslinking between chitosan (CS) and oxidized xanthan gum (OXG) provided through Schiff base linkages results in a self-healing material. Schiff bases or imine bonds are formed between the aldehyde's interaction (in the oxidized xanthan gum, OXG) and the amine functional groups (provided by chitosan, CS). These linkages based on aromatic derivatives have relatively greater stability than their aliphatic counterparts. Schiff bases can dynamically uncouple and recouple, resulting in self-healing and injectability properties in their network structure $[6,15]$. In the past years, dynamic hydrogels created based on Schiff bases have been widely used in industrial and biomedical applications. Schiff base linkage keeps a balance between breakage and regeneration, leading to the hydrogel's remarkable self-healing properties. The incorporation of stable silica-modified magnetite nanoparticles well-dispersed in the CS-OXG hydrogels results in relatively stronger materials than CS-OXG hydrogels (unfilled).

\section{Materials and Methods}

\subsection{Materials.}

Chitosan in medium molecular weight (MMW), concentrated acetic acid, sulfuric acid $\left(\mathrm{H}_{2} \mathrm{SO}_{4}\right)$, absolute ethanol $(\mathrm{EtOH})$, hydrochloric acid $(\mathrm{HCl})$, and ammonium hydroxide $\left(\mathrm{NH}_{4} \mathrm{OH}\right)$, as well as solid ferric sulfate $\left(\mathrm{FeSO}_{4}\right)$, ferric chloride $\left(\mathrm{FeCl}_{3}\right)$, hydroxylamine hydrochloric acid $\left(\mathrm{NH}_{2} \mathrm{OH}(\mathrm{HCl})\right)$, xanthan gum, chitosan, tetraethyl orthosilicate (TEOS), and potassium metaperiodate $\left(\mathrm{NaIO}_{4}\right)$ were obtained from Sigma-Aldrich.

The oxidized xanthan gum (OXG) used (with $45 \%$ aldehyde content) was prepared via periodate oxidation as reported elsewhere [32, 33].

\subsection{Synthesis of magnetite nanoparticles $\left(\mathrm{Fe}_{3} \mathrm{O}_{4}\right)$.}

$\mathrm{The} \mathrm{Fe}_{3} \mathrm{O}_{4}$ nanoparticles were synthesized via a modified co-precipitation method based on the work of Yazdani and Seddigh (2016) [34]. In a 250-mL round bottom flask, $26.4 \mathrm{~mL}$ of $0.1 \mathrm{M} \mathrm{FeCl}_{3}, 13.2 \mathrm{~mL}$ of $\mathrm{FeSO}_{4}$, and $182.64 \mathrm{~mL}$ of distilled water were combined using syringes stirring at $800 \mathrm{rpm}$ and $60{ }^{\circ} \mathrm{C}$. The reaction flask was maintained under a nitrogen atmosphere by connecting a balloon containing nitrogen gas. Afterward, to initiate the precipitation, $18.2 \mathrm{~mL}$ of $1 \mathrm{M} \mathrm{NaOH}$ was added into the mixture and a sufficient amount of distilled water for washing after 1 minute. The black precipitates were then collected at one of the flask using a strong neodymium magnet and decanted for subsequent washings. The collected black precipitates were washed with distilled water several times and dried under a vacuum overnight.

\subsection{Surface modification of silica-modified magnetite nanoparticles $\left(\mathrm{Fe}_{3} \mathrm{O}_{4} @ \mathrm{SiO}_{2}\right)$.}

In modifying the surface of the previously synthesized magnetite nanoparticles, a modified Stöber method (Thangaraj, 2016) [35] was used. About $4 \mathrm{~g}$ of $\mathrm{Fe}_{3} \mathrm{O}_{4}$ was then dispersed in $180 \mathrm{~mL}$ absolute ethanol and $20 \mathrm{~mL}$ distilled water under sonication. Afterward, with a 1:1 weight ratio of $\mathrm{Fe}_{3} \mathrm{O}_{4}$ with TEOS, $4 \mathrm{~mL}$ of TEOS and $10 \mathrm{~mL}$ of $25 \%$ ammonium 
hydroxide were added dropwise into the mixture and stirred for 6 hours. The resulting particles were collected using a magnet and thoroughly washed with ethanol and distilled water. The final products were freeze-dried for subsequent use.

\subsection{Synthesis of magnetic biopolymeric hydrogel composite (CS-OXG-MNP).}

Initially, a chitosan solution ( $3 \%, \mathrm{w} / \mathrm{w})$ was prepared by dissolving $0.30 \mathrm{~g}$ of chitosan powder into $10 \mathrm{~mL}$ of acetic acid ( $2 \%$, v/v) aqueous solution. Right after, $0.09 \mathrm{~g}$ of $\mathrm{Fe}_{3} \mathrm{O}_{4} @ \mathrm{SiO}_{2}$ nanopowder was added into the chitosan solution. Subsequently, it was stirred vigorously, followed by sonication for 1 hour to produce the target black homogenous gel of the chitosan $\mathrm{Fe}_{3} \mathrm{O}_{4} @ \mathrm{SiO}_{2}$ (CS-MNP). This CS-MNP composite gel was isolated by exposing it to the external magnetic field.

In preparing and synthesizing the magnetic self-healing hydrogel, $0.30 \mathrm{~g}$ of oxidized xanthan gum was dissolved in $3.5 \mathrm{~mL}$ distilled water. The $\mathrm{OXG}$ solution was then added to the CS-MNP composite gel and was stirred under $500 \mathrm{rpm}$ and $40^{\circ} \mathrm{C}$ for about 30 minutes. Finally, the CS-OXG-MNP hydrogel was transferred and molded into a square-like shape in acetate films and air-dried for 6 hours.

\subsection{Characterization.}

2.5.1. Fourier transform infrared (FT-IR) spectroscopic measurements.

An FT-IR spectrophotometer was used to obtain the FT-IR spectra of $\mathrm{Fe}_{3} \mathrm{O}_{4}$ (unmodified) and $\mathrm{Fe}_{3} \mathrm{O}_{4} @ \mathrm{SiO}_{2}$ (modified) to follow the silica-modification of the magnetic $\mathrm{Fe}_{3} \mathrm{O}_{4}$ nanoparticles employing $\mathrm{KBr}$ pellet technique at room temperature in the wavenumber range of $4000-500 \mathrm{~cm}^{-1}$. The samples were pulverized to obtain a powder and were mixed with $\mathrm{KBr}$. It was then molded into a $\mathrm{KBr}$ pellet. Each of the spectra was obtained after 16 scans.

\subsubsection{Self-healing tests.}

The self-healing tests were done by slicing the hydrogel into two parts using a thin glass slide. The two separated portions were placed side-by-side, directly interacting with each other and given ample time to self-heal. The duration until the hydrogel fully self-healed was recorded for each set-up. The self-healed hydrogels were then lifted to show that the linkages were restored.

For the hydrogel matrix based on the two polymers, different weight ratios were considered in the hydrogel preparation to determine the best combination for a hydrogel film that exhibited better film formation characteristic, faster self-healing time, and stronger mechanical property. This was exhibited in CS-OXG with 1:1 weight ratio among various ratios considered, as reported in an earlier paper we published [33].

\subsubsection{Scanning electron microscopy (SEM) analyses.}

The nanoparticles' structure and morphology $\left(\mathrm{Fe}_{3} \mathrm{O}_{4} \& \mathrm{Fe}_{3} \mathrm{O}_{4} @ \mathrm{SiO}_{2}\right)$ used in the experiment were characterized by scanning electron microscopy (SEM). The sizes of the particles were also determined and averaged. All samples were freeze-dried before the SEM tests. The gold coating was applied through sputtering for better magnification. 


\section{Results and Discussion}

\subsection{Preparation and characterization of the inorganic magnetic particles as nanofillers.}

Magnetite nanoparticles were successfully synthesized using the co-precipitation method. The black particles rapidly precipitated as soon as the $\mathrm{NaOH}$ was added. The concentrations of the reagents used were optimized to obtain the smallest and most uniform nanoparticles. It was found out that at $0.1 \mathrm{M}$ concentration of $\mathrm{FeCl}_{3}$ and $\mathrm{FeSO}_{4}$, smaller and less agglomerated particles were produced. Furthermore, according to Mahdavi et al. (2013) [36], the temperature of $60^{\circ} \mathrm{C}$ and $800 \mathrm{rpm}$ are necessary to reduce the extent of agglomeration and, in turn, reduce the sizes of the particles. It is also important to note that the dried particles are sensitive and easily agglomerate when exposed to air.

The synthesized magnetic nanoparticles $\left(\mathrm{Fe}_{3} \mathrm{O}_{4}\right)$ were consequently coated with silicon dioxide $\left(\mathrm{SiO}_{2}\right)$ by reacting with tetraethyl orthosilicate (TEOS), serving as a surface modifying agent) for stability and functional purposes. The modified nanoparticles were very responsive to the external magnet, as shown in Figure 1, and settled at the container's bottom without the magnet. For this experiment, the ratio of $1: 1$ ( $\mathrm{Fe}_{3} \mathrm{O}_{4}$ :TEOS) was used according to the previously mentioned method.

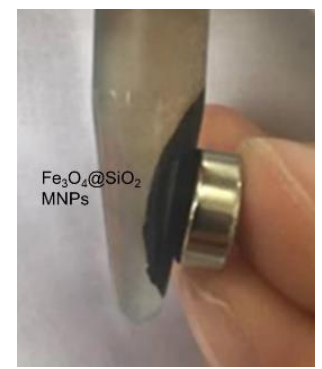

Figure 1. Silica-modified magnetite $\left(\mathrm{Fe}_{3} \mathrm{O}_{4} @ \mathrm{SiO}_{2}\right)$ nanoparticles attracted to a magnet.

The synthesis of magnetite nanoparticles was successfully followed by FT-IR spectroscopic measurements of the materials. As shown in Figure 2, Fe-O bonding around 600 $\mathrm{cm}^{-1}$ is more prominent in the uncoated particles. For the coated ones, a peak became prominent at around $1100 \mathrm{~cm}^{-1}$ which denotes the presence of Fe-O-Si bands and the success in modifying the magnetite particles' surfaces.

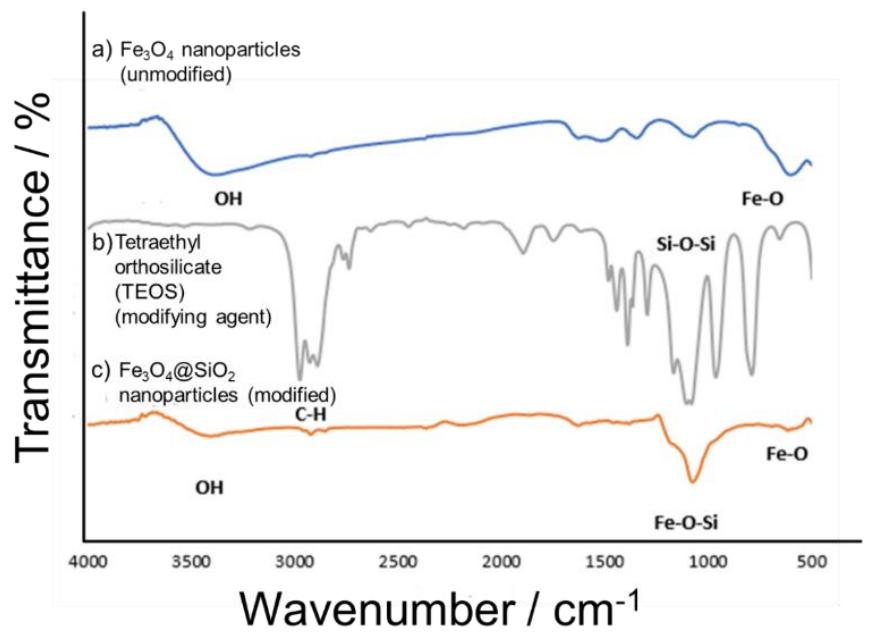

Figure 2. FT-IR spectra of a) unmodified magnetite $\left(\mathrm{Fe}_{3} \mathrm{O}_{4}\right)$ nanoparticles; b) tetraethyl orthosilicate (TEOS) as the surface modifying agent) and c) silica-modified magnetite $\left(\mathrm{Fe}_{3} \mathrm{O}_{4} @ \mathrm{SiO}_{2}\right)$ nanoparticles. 
Scanning electron micrographs (SEM) of the magnetite $\mathrm{Fe}_{3} \mathrm{O}_{4}$ nanoparticles (unmodified) and silica-modified magnetite, $\mathrm{Fe}_{3} \mathrm{O}_{4} @ \mathrm{SiO}_{2}$ (modified) are shown in Figure 3. Comparison of the SEM images reveals the uncoated magnetite nanoparticles indeed agglomerated as opposed to the modified nanoparticles. $\mathrm{Fe}_{3} \mathrm{O}_{4} @ \mathrm{SiO}_{2}$ (modified) appeared spherical in shape and existed as isolated particles (dispersed). The average diameter is about $55 \mathrm{~nm}$.
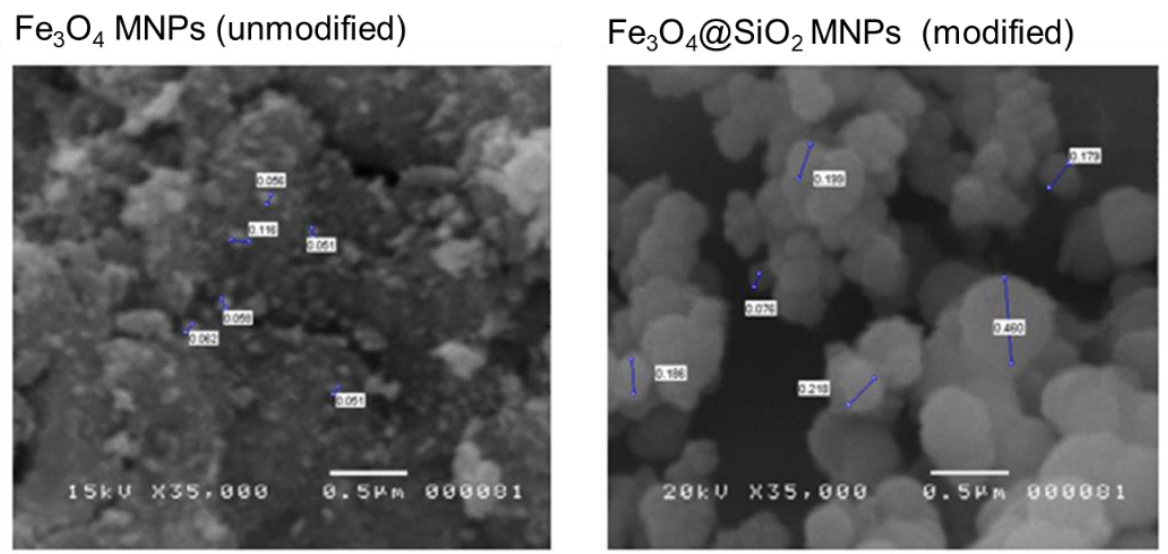

Figure 3. Scanning electron micrographs (SEM) of unmodified magnetite $\left(\mathrm{Fe}_{3} \mathrm{O}_{4}\right)$ (left) and silica-modified magnetite $\left(\mathrm{Fe}_{3} \mathrm{O}_{4} @ \mathrm{SiO}_{2}\right)$ magnetic nanoparticles (MNPs) (right). The bar scale is $0.5 \mu \mathrm{m}$.

3.2. Preparation and characterization of the magnetic biopolymeric hydrogel composite.

Both CS-OXG (1:1) and CS-OXG-MNP (1:1:0.2) hydrogel samples successfully selfhealed at ambient room conditions (Figure 4). These hydrogels self-healed even when they were cut into small pieces. For the CS-OXG (1:1), it was able to self-heal after 1 hour and 30 minutes after cut portions were made to come in contact.

\section{CS:OXG (1:1) hydrogel}

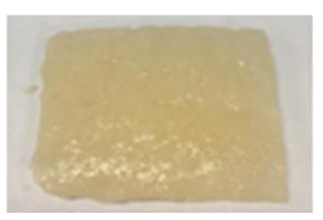

Before cutting

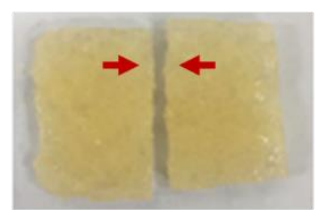

Cut portions

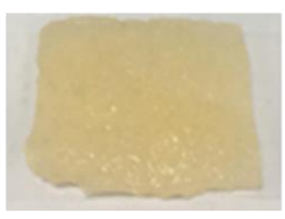

Healed

\section{CS:OXG:MNP (1:1:0.2) hydrogel composite}

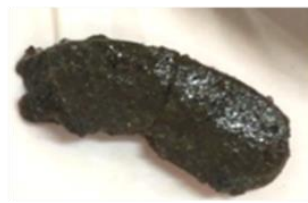

Before cutting

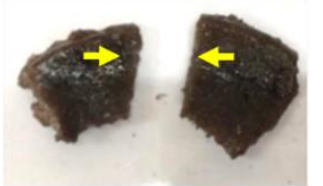

Cut portions

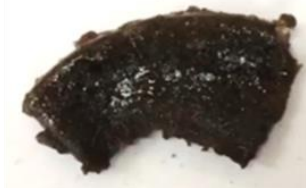

Healed

Figure 4. Self-healing tests of CS:OXG (at 1:1 weight ratios) hydrogel - unfilled) (top) and CS:OXG:MNP hydrogel composite at (1:1:0.2 weight ratios, respectively) (bottom).

In the case of adding the silica-modified magnetic nanoparticles in the hydrogel, CSOXG-MNP (1:1:0.2), self-healing characteristic was observed much earlier, an hour. As expected, it was able to withstand heavier counterweights $(11.78 \mathrm{~g}), 55 \%$ greater than CS-OXG of ratio 1:1 (6.50 g) (Figure 5). 


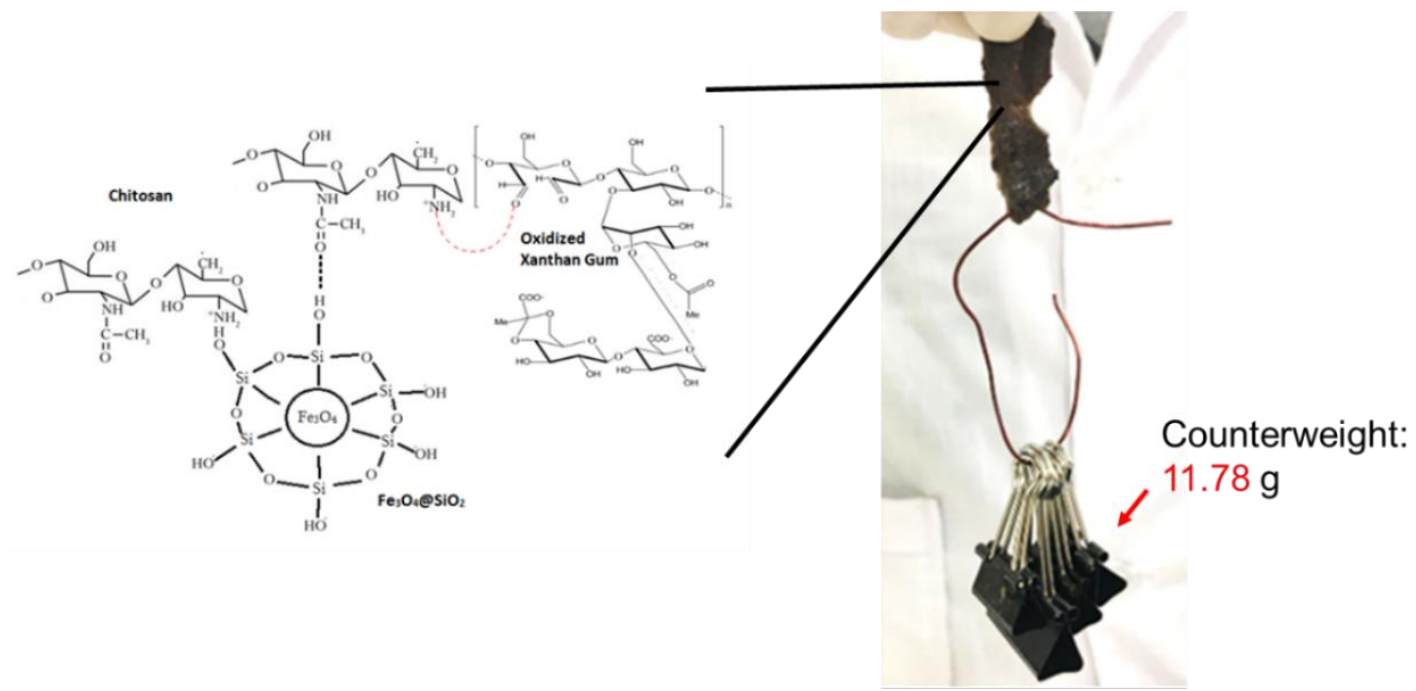

Figure 5. CS:OXG:MNP hydrogel composite subjected to a counterweight after being self-healed.

\section{Conclusions}

A novel polysaccharide-based magnetic self-healing hydrogel was successfully prepared. The hydrogel used as a matrix was based on two natural polysaccharide polymers, chitosan, and oxidized xanthan gum, via Schiff base interaction. The FT-IR analyses' results proved that the crosslinking of CS and OXG formed dynamic Schiff base linkages. The incorporation of a surface-modified magnetic nanoparticle $\left(\mathrm{Fe}_{3} \mathrm{O}_{4} @ \mathrm{SiO}_{2}\right)$ in the hydrogel resulted in better properties than the unfilled CS-OXG hydrogel in terms of faster self-healing characteristics and stronger mechanical property.

\section{Funding}

This research received no external funding.

\section{Acknowledgments}

The De La Salle University, through its University Research Coordination Office (URCO) is acknowledged for the article manuscript writing fund extended to the authors.

\section{Conflicts of Interest}

The authors declare no conflict of interest.

\section{References}

1. Du, S.; Chen, X.; Chen, X.; Li, S.; Yuan, G.; Zhou, T.; Li, J.; Jia, Y.; Xiong, D.; Tan, H. Covalent chitosancellulose hydrogels via schiff-base reaction containing macromolecular microgels for $\mathrm{pH}$-sensitive drug delivery and wound dressing. Macromolecular Chemistry and Physics 2019, 220.

2. Hu, W.; Wang, Z.; Xiao, Y.; Zhang, S.; Wang, J. Advances in crosslinking strategies of biomedical hydrogels. Biomaterials Science 2019, 7, 843-855, https://doi.org/10.1039/c8bm01246f.

3. Zidan, T.A.; Abdelhamid, A.E.; Zaki, E.G. N-Aminorhodanine modified chitosan hydrogel for antibacterial and copper ions removal from aqueous solutions. International Journal of Biological Macromolecules 2020, 158, 32-42, https://doi.org/10.1016/j.ijbiomac.2020.04.180.

4. Shundo, A.; Hoshino, Y.; Higuchi, T.; Matsumoto, Y.; Penaloza Jr, D.P.; Matsumoto, K.; Ohno, M.; Miyaji, K.; Goto, M.; Tanaka, K. Facile microcapsule fabrication by spray deposition of a supramolecular hydrogel. RSC Advances 2014, 4, 36097-36100, https://doi.org/10.1039/c4ra04636f.

5. Nematidil, N.; Sadeghi, M.; Nezami, S.; Sadeghi, H. Synthesis and characterization of Schiff-base based chitosan-g-glutaraldehyde/NaMMTNPs-APTES for removal $\mathrm{Pb}^{2+}$ and $\mathrm{Hg}^{2+}$ ions. Carbohydrate Polymers 2019, 222, https://doi.org/10.1016/j.carbpol.2019.114971. 
6. Zhou, L.; Chen, M.; Guan, Y.; Zhang, Y. Multiple responsive hydrogel films based on dynamic Schiff base linkages. Polymer Chemistry 2014, 5, 7081-7089, https://doi.org/10.1039/C4PY00868E.

7. Hori, K.; Penaloza, D.P.; Shundo, A.; Tanaka, K. Time-dependent heterogeneity in viscoelastic properties of worm-like micelle solutions. Soft Matter 2012, 8, 7361-7364, https://doi.org/10.1039/c2sm25549a.

8. Shundo, A.; Penaloza, D.P.; Tanaka, K. Microscopic heterogeneity in viscoelastic properties of molecular assembled systems. Chinese Journal of Polymer Science 2013, 31, 1-11, https://doi.org/10.1007/s10118013-1193-z.

9. Shundo, A.; Hori, K.; Penaloza, D.P.; Tanaka, K. Optical tweezers with fluorescence detection for temperature-dependent microrheological measurements. Review of Scientific Instruments 2013, 84, https://doi.org/10.1063/1.4789429.

10. Neacsu, I.A.; Melente, A.E.; Holban, A.M.; Ficai, A.; Ditu, L.M.; Kamerzan, C.M.; Tihauan, B.M.; Nicoara, A.I.; Chifiriuc, M.C.; Pircalabioru, G. Novel hydrogels based on collagen and ZnO nanoparticles with antibacterial activity for improved wound dressings. Romanian Biotechnological Letters 2019, 24, 317323, https://doi.org/10.26327/RBL2018.239

11. Xu, S.; Li, H.; Ding, H.; Fan, Z.; Pi, P.; Cheng, J.; Wen, X. Allylated chitosan-poly(N-isopropylacrylamide) hydrogel based on a functionalized double network for controlled drug release. Carbohydrate Polymers 2019, 214, 8-14, https://doi.org/10.1016/j.carbpol.2019.03.008.

12. Hamed, A.A.; Abdelhamid, I.A.; Saad, G.R.; Elkady, N.A.; Elsabee, M.Z. Synthesis, characterization and antimicrobial activity of a novel chitosan Schiff bases based on heterocyclic moieties. International Journal of Biological Macromolecules 2020, 153, 492-501, https://doi.org/10.1016/j.ijbiomac.2020.02.302.

13. Wang, Y.; Xie, R.; Li, Q.; Dai, F.; Lan, G.; Shang, S.; Lu, F. A self-adapting hydrogel based on chitosan/oxidized konjac glucomannan/AgNPs for repairing irregular wounds. Biomaterials Science 2020, 8, 1910-1922, https://doi.org/10.1039/C9BM01635J.

14. Liu, Q.; Ji, N.; Xiong, L.; Sun, Q. Rapid gelling, self-healing, and fluorescence-responsive chitosan hydrogels formed by dynamic covalent crosslinking. Carbohydrate Polymers 2020, 246, https://doi.org/10.1016/j.carbpol.2020.116586.

15. Morozowich, N.L.; Nichol, J.L.; Allcock, H.R. Hydrogels based on schiff base formation between an aminocontaining polyphosphazene and aldehyde functionalized-dextrans. Journal of Polymer Science Part A: Polymer Chemistry 2016, 54, 2984-2991, https://doi.org/10.1002/pola.28184.

16. Ene, V.L.; Neacsu, I.A.; Oprea, O.; Surdu, V.A.; Trusca, R.D.; Ficai, A.; Andronescu, E. Single step synthesis of glutamic/tartaric acid-stabilised $\mathrm{Fe}_{3} \mathrm{O}_{4}$ nanoparticles for targeted delivery systems. Revista de Chimie 2020, 71, 230-238, 2020, https://doi.org/10.37358/rc.20.2.7920.

17. Brigger, I.; Dubernet, C.; Couvreur, P. Nanoparticles in cancer therapy and diagnosis. Advanced Drug Delivery Reviews 2012, 64, 24-36, https://doi.org/10.1016/j.addr.2012.09.006.

18. Gupta, A.K.; Gupta, M. Synthesis and surface engineering of iron oxide nanoparticles for biomedical applications. Biomaterials 2005, 26, 3995-4021, https://doi.org/10.1016/j.biomaterials.2004.10.012.

19. Laurent, S.; Forge, D.; Port, M.; Roch, A.; Robic, C.; Vander Elst, L.; Muller, R.N. Magnetic iron oxide nanoparticles: synthesis, stabilization, vectorization, physicochemical characterizations, and biological applications. Chemical Reviews 2008, 108, 2064-2110, https://doi.org/10.1021/acs.langmuir.5b03192.

20. Lu, A.-H.; Salabas, E.L.; Schüth, F. Magnetic Nanoparticles: Synthesis, Protection, Functionalization, and Application. Angewandte Chemie International Edition 2007, 46, 1222-1244, https://doi.org/10.1002/anie.200602866.

21. Mornet, S.; Vasseur, S.; Grasset, F.; Duguet, E. Magnetic nanoparticle design for medical diagnosis and therapy. Journal of Materials Chemistry 2004, 14, 2161-2175, https://doi.org/10.1039/B402025A.

22. Tartaj, P.; Morales, M.A.D.P.; Veintemillas-Verdaguer, S.; Gonz lez-Carre o, T.; Serna, C.J. The preparation of magnetic nanoparticles for applications in biomedicine. Journal of Physics D: Applied Physics 2003, 36, R182-R197, https://doi.org/10.1088/0022-3727/36/13/202.

23. Ito, A.; Shinkai, M.; Honda, H.; Kobayashi, T. Medical application of functionalized magnetic nanoparticles. Journal of Bioscience and Bioengineering 2005, 100, 1-11, https://doi.org/10.1263/jbb.100.1.

24. Mohammadi Ziarani, G.; Malmir, M.; Lashgari, N.; Badiei, A. The role of hollow magnetic nanoparticles in drug delivery. RSC Advances 2019, 9, 25094-25106, https://doi.org/10.1039/C9RA01589B.

25. Ayubi, M.; Karimi, M.; Abdpour, S.; Rostamizadeh, K.; Parsa, M.; Zamani, M.; Saedi, A. Magnetic nanoparticles decorated with PEGylated curcumin as dual targeted drug delivery: Synthesis, toxicity and biocompatibility study. Materials Science and Engineering: C 2019, 104, https://doi.org/10.1016/j.msec.2019.109810.

26. Sun, C.; Lee, J.S.H.; Zhang, M. Magnetic nanoparticles in MR imaging and drug delivery. Advanced Drug Delivery Reviews 2008, 60, 1252-1265, https://doi.org/10.1016/j.addr.2008.03.018.

27. Salmani, M.M.; Hashemian, M.; Yekta, H.J.; Nejad, M.G.; Saber-Samandari, S.; Khandan, A. Synergic Effects of Magnetic Nanoparticles on Hyperthermia-Based Therapy and Controlled Drug Delivery for Bone Substitute Application. Journal of Superconductivity and Novel Magnetism 2020, 33, 2809-2820, https://doi.org/10.1007/s10948-020-05530-1. 
28. Moradnia, F.; Taghavi Fardood, S.; Ramazani, A.; Gupta, V.K. Green synthesis of recyclable MgFeCrO4 spinel nanoparticles for rapid photodegradation of direct black 122 dye. Journal of Photochemistry and Photobiology A: Chemistry 2020, 392, https://doi.org/10.1016/j.jphotochem.2020.112433.

29. Zhang, Y.; Ni, S.; Wang, X.; Zhang, W.; Lagerquist, L.; Qin, M.; Willför, S.; Xu, C.; Fatehi, P. Ultrafast adsorption of heavy metal ions onto functionalized lignin-based hybrid magnetic nanoparticles. Chemical Engineering Journal 2019, 372, 82-91, https://doi.org/10.1016/j.cej.2019.04.111.

30. Liu, X.; Hu, Q.; Fang, Z.; Zhang, X.; Zhang, B. Magnetic Chitosan Nanocomposites: A Useful Recyclable Tool for Heavy Metal Ion Removal. Langmuir 2009, 25, 3-8, https://doi.org/10.1021/la802754t.

31. Lü, T.; Ma, R.; Ke, K.; Zhang, D.; Qi, D.; Zhao, H. Synthesis of gallic acid functionalized magnetic hydrogel beads for enhanced synergistic reduction and adsorption of aqueous chromium. Chemical Engineering Journal 2021, 408, https://doi.org/10.1016/j.cej.2020.127327.

32. Almomani, F.; Bhosale, R.; Khraisheh, M.; kumar, A.; Almomani, T. Heavy metal ions removal from industrial wastewater using magnetic nanoparticles (MNP). Applied Surface Science 2020, 506, https://doi.org/10.1016/j.apsusc.2019.144924.

33. Salazar, G.M.; Sanoh, N.C.; Penaloza, D.P. Synthesis and characterization of a novel polysaccharide-based self-healing hydrogel. KIMIKA 2018, 29, 44-48, https://doi.org/10.26534/kimika.v29i2.44-48.

34. Yazdani, F.; Seddigh, M. Magnetite nanoparticles synthesized by co-precipitation method: The effects of various iron anions on specifications. Materials Chemistry and Physics 2016, 184, 318-323, https://doi.org/10.1016/j.matchemphys.2016.09.058.

35. Thangaraj, B.; Jia, Z.; Dai, L.; Liu, D.; Du, W. Effect of silica coating on $\mathrm{Fe}_{3} \mathrm{O}_{4}$ magnetic nanoparticles for lipase immobilization and their application for biodiesel production. Arabian Journal of Chemistry 2019, 12, 4694-4706, https://doi.org/10.1016/j.arabjc.2016.09.004.

36. Mahdavi, M.; Namvar, F.; Ahmad, B. M.; Mohamad, R. Green biosynthesis and characterization of magnetic iron oxide $\left(\mathrm{Fe}_{3} \mathrm{O}_{4}\right)$ nanoparticles using seaweed (Sargassum muticum) aqueous extract. Molecules 2013, 18, 5954-5964, https://doi.org/10.3390/molecules18055954. 